Tropical Journal of Pharmaceutical Research January 2021; 20 (1): 197-201

ISSN: $1596-5996$ (print); 1596-9827 (electronic) (C) Pharmacotherapy Group, Faculty of Pharmacy, University of Benin, Benin City, 300001 Nigeria.

\title{
Assessment of medication prescription errors and their contributory factors in major cities of Punjab Province, Pakistan: A cross-sectional survey
}

\author{
Abdul Majeed ${ }^{1}$, Iltaf Hussain ${ }^{1}$, Muqarrab Akbar ${ }^{2}$, Muhammad O Chaudhry $^{3}$, \\ Imran Imran ${ }^{4}$, Hamid Saeed ${ }^{5}$, Furqan K Hashmi ${ }^{5}$, Omama Siddique ${ }^{1}$, Shehnoor \\ Tahir $^{1}$, Sana Bilal, Fazila Ashraf ${ }^{1}$, Mehvish Ayaz ${ }^{1}$, Muhammad F Rasool ${ }^{1 *}$ \\ ${ }^{1}$ Department of Pharmacy Practice, ${ }^{2}$ Department of Political Science, ${ }^{3}$ School of Economics, ${ }^{4}$ Department of Pharmacology, \\ Faculty of Pharmacy, Bahauddin Zakariya University, 60800, Multan, ${ }^{5}$ University College of Pharmacy, Allama Iqbal Campus, \\ University of the Punjab, 54000, Lahore, Pakistan
}

*For correspondence: Email: fawadrasool@bzu.edu.pk; Tel: +92-3008639046

Sent for review: 23 July 2020

Revised accepted: 15 December 2020

\begin{abstract}
Purpose: To evaluate the prescription errors and their contributory factors in Punjab, Pakistan. Methods: An observational, cross-sectional study was conducted in 12 major cities of Punjab, Pakistan. A total of 1,184 prescriptions were collected from patients using a convenient sampling method from homes, pharmacies, clinics, and hospitals. The data were presented in frequency and percentage using descriptive statistics. To determine the association between the variables assessed, Chi-square ( 2) test was used.

Results: A total of 1,184 prescriptions were analyzed; 432 of them (36.5\%) were from prescribers who are graduate degree holders, and 752 (63.5 \%) from prescribers who are post-graduate degree holders. The most commonly missing parameters in the prescriptions were the age of the patients (835 representing $29.4 \%$ ), signatures of the prescribers (755 representing $26.5 \%$ ), and prefix (622 representing $21.9 \%)$. The number of prescription errors was significantly correlated to prescriber qualification $(p=0.001)$. The prescription errors were more common in age groups of prescribers: 21 30 years (654 representing $23.0 \%)$, and 31 - 40 years (1,012 representing $35.6 \%)(p=0.001)$. The higher number of prescription errors by post-graduate prescribers working in teaching hospitals can be attributed to the higher patient load and lack of continuing medical education programs for the prescribers.

Conclusion: The government should take necessary measures for the implementation of electronic prescribing systems, and devise mechanisms for the uniform distribution of patient load amongst the prescribers working in different hospitals.
\end{abstract}

Keywords: Prescription error, Prescribers, Patient load, Continuing medical education, Electronic prescribing

This is an Open Access article that uses a fund-ing model which does not charge readers or their institutions for access and distributed under the terms of the Creative Commons Attribution License (http://creativecommons.org/licenses/by/4.0) and the Budapest Open Access Initiative (http://www.budapestopenaccessinitiative.org/read), which permit unrestricted use, distribution, and reproduction in any medium, provided the original work is properly credited.

Tropical Journal of Pharmaceutical Research is indexed by Science Citation Index (SciSearch), Scopus, International Pharmaceutical Abstract, Chemical Abstracts, Embase, Index Copernicus, EBSCO, African Index Medicus, JournalSeek, Journal Citation Reports/Science Edition, Directory of Open Access Journals (DOAJ), African Journal Online, Bioline International, Open-J-Gate and Pharmacy Abstracts

(c) 2021 Majeed A, Hussain I, Akbar M, Chaudhry MO, Imran I, Saeed H, Hashmi FK, Siddique O, Tahir S, Bilal S, Ashraf F, Ayaz M, Rasool MF. This work is licensed under the Creative Commons Attribution 4.0 International License 


\section{INTRODUCTION}

Prescription writing is a science and art which provides information regarding medication use to the patient, and it is the responsibility of the prescriber [1]. A prescription is a signed medical order which has the instructions to the pharmacist by the prescriber on how to supply the prescribed drugs to the specific patients. It is a medico-legal document that is written completely, precisely, and legally [2]. The core components of a prescription are prescriber information, patient information, date, superscription, inscription, subscription, signature, and prescriber signature $[3,4]$.

A prescription error is a failure in the prescription writing or filling process which leads to a wrong instruction about one or more components of the prescription [5]. The most common prescription errors encountered during prescription writing are errors of omission and commission [2]. The error of omission represents incomplete prescriptions like missing patient information, incomplete instruction regarding dosage, dosage form, and illegible prescription (difficult to read because of bad handwriting). The error of commission comprises wrong information regarding the drug or patient, which includes wrong drug, wrong route, dosage form or strength $[6,7]$.

Prescription is an integral and vital component for the provision of health. According to the National Coordinating Council for Medication Error Reporting and Prevention, about 0.1 million people die every year as a result of medication errors [6]. World Health Organization (WHO) stated that each year in Pakistan, about 0.5 million people die due to medication errors, and this number can reach 10 million by the year 2050 [7].

It has been seen that there is a gap in the incidence and reporting of prescription errors in developed countries, as only $25 \%$ of the prescription errors were reported [8]. Since Pakistan is a developing country and there is no legal reporting mechanism for the incidence of prescription errors in the retail pharmacies, the situation here can be very alarming [9]. Therefore, the studies that can identify the incidence of prescription errors can be very useful in developing policies and frameworks for the prevention of prescription-related medication errors [10].

The aim of the study was to evaluate the prescription errors and the factors that contribute to it in the most populous province in Pakistan.

\section{METHODS}

\section{Study design and data collection}

An observation based cross-sectional study was performed in 12 major cities in Punjab, Pakistan. Ethical approval was granted by the ethical committee of Department of Pharmacy Practice, Faculty of Pharmacy, Bahauddin Zakariya University, Multan, Pakistan. A total of 1,184 prescriptions were collected from patients using a convenient sampling method from homes, pharmacies, clinics, and hospitals. The prescribers were grouped into two categories based on their qualification as graduate and post-graduate (Table 1).

Prescriptions were evaluated by comparing the written prescriptions with international guidelines/standards of WHO which includes patient data on age, gender and therapy-related information like drug strength, prefix, date of prescription, dose, duration of therapy and the signature of physician [3].

\section{Inclusion/exclusion criteria}

Only handwritten prescriptions were collected and not more than one prescription was taken from each patient. Both male and female patients of all age groups were included in the study.

Table 1: Prescriber groups and their qualification

\begin{tabular}{ll}
\hline $\begin{array}{l}\text { Prescriber's } \\
\text { group }\end{array}$ & Qualification \\
\hline Graduate & $\begin{array}{l}\text { Bachelor of Medicine and } \\
\text { Bachelor of Surgery (MBBS) } \\
\\
\text { Fellow of the College of }\end{array}$ \\
Postgraduate & $\begin{array}{l}\text { Physicians and Surgeons (FCPS) } \\
\text { Member of the College of } \\
\end{array}$ \\
& Physicians and Surgeons (MCPS) \\
\hline
\end{tabular}

\section{Statistical analysis}

Statistical Package for Social Sciences (SPSS, IBM Corp. Armonk, NY) was used for Statistical analysis. To summarize the data, descriptive statistics were used. For the categorical variables, the chi-square $\left(\chi^{2}\right)$ test was used to investigate the association between the variables, and $p<0.05$ was stated as statistically significant.

\section{RESULTS}

Among the total 1,184 prescriptions, 562 (47.5 $\%)$ were male, and $622(52.5 \%)$ were female. The mean age of the patient was 19.9 \pm 28.6 . The total number of prescribers was 1,172, among which $432(36.5 \%)$ are graduate degree holders, 
and 752 (63.5 \%) are post-graduate degree holders. The most common missing parameters were age (835 representing $29.4 \%$ ), signature (755 representing $26.5 \%$ ), and prefix (622 representing $21.9 \%$ ), as shown in Table 2 . The frequency and percentage of collected prescriptions from different cities can be seen in Table 3. The number of identified prescription errors was higher in prescribers with postgraduate qualifications (1,876 representing 66 $\%$ ), than prescribers with graduate qualifications (933 representing $33.9 \%$ ). The number of prescription errors was significantly related to the prescriber qualification $(p=0.001)$. Among hospitals, a higher number of prescription errors were seen in teaching hospitals $(1,472$ representing $51.1 \%$ ), followed by district headquarter hospitals (934 representing $32.8 \%$ ), and private hospitals (433 representing $15.2 \%$ ) $(p=0.27)$. The number of prescription errors in male and female were 1,216 (42.8\%) and 1,623 $(57.1 \%)$ respectively. There was no significant difference among the gender of the patients $(p=0.09)$. The prescription errors were more common in age groups of $21-30$ years (654 representing $23.0 \%$ ), and $31-40$ years $(1,012$ representing $35.6 \%)(p=0.001)$ (Table 4).

\section{DISCUSSION}

In the current study, 1,184 prescriptions were collected from different cities in Punjab, Pakistan and the total number of prescription errors was 2,839 . The most common missing parameters were, age (835 representing $29.4 \%$ ), signature (755 representing $26.6 \%$ ), and prefix (622 representing $21.9 \%$ ). Prescription errors were more common in postgraduate prescribers
(1,876 representing $66.1 \%)$, as compared to graduate prescribers (933 representing $33.9 \%$ ). Most of the prescription errors were within the age group of 21-30 years (654 representing 23.0 $\%)$ and $31-40$ years (1,012 representing $35.6 \%)$.

The frequency of prescription errors in the current study was 2,839 (41.7\%), which was lower than reported in UK (77.4\%) [12], and Sri Lanka (91\%) [13].

Table 2: Frequency of different missing parameters ( $\mathrm{n}$ $=2,839$ )

\begin{tabular}{lcc}
\hline Parameter & N & Percent \\
\hline Age & 835 & 29.4 \\
Gender & 104 & 3.6 \\
Strength & 300 & 3.6 \\
Signature & 755 & 26.5 \\
Prefix & 622 & 21.9 \\
Address & 164 & 5.7 \\
Date & 19 & 0.6 \\
\hline
\end{tabular}

Table 3: Frequency of prescriptions collected from different Pakistani cities $(n=1,184)$

\begin{tabular}{lcc}
\hline City & N & Percent \\
\hline Burewla & 96 & 8.1 \\
Khanewal & 97 & 8.2 \\
Okara & 97 & 8.2 \\
Layyah & 97 & 8.2 \\
Muzaffargarh & 97 & 8.2 \\
Sahiwal & 98 & 8.3 \\
Pakpattan & 96 & 8.1 \\
Gujranwala & 110 & 9.3 \\
Faisalabad & 96 & 8.1 \\
Lahore & 102 & 8.6 \\
Multan & 102 & 8.6 \\
DG Khan & 96 & 8.1 \\
\hline
\end{tabular}

Table 4: Association of prescription errors with different variables

\begin{tabular}{|c|c|c|c|}
\hline Variable & $\mathbf{N}(\%)$ & $\begin{array}{c}\geq 1 \text { Prescription } \\
\text { error, } \mathbf{N}(\%)\end{array}$ & $P$-value \\
\hline Prescriber qualification $(\mathrm{n}=1172)$ & & $2839(41.7)$ & \multirow{3}{*}{0.001} \\
\hline Graduate & $432(36.5)$ & $963(33.9)$ & \\
\hline Post-graduate & $752(63.5)$ & $1876(66.0)$ & \\
\hline Hospital $(n=1156)$ & & & \\
\hline Teaching hospital & $472(39.9)$ & $1472(51.1)$ & \multirow{3}{*}{0.27} \\
\hline District Headquarter Hospital (DHQ) & $329(27.8)$ & $934(32.8)$ & \\
\hline Private & $355(30.0)$ & $433(15.2)$ & \\
\hline Gender of patients $(n=1184)$ & & & \multirow{3}{*}{0.09} \\
\hline Male & $562(47.5)$ & $1216(42.8)$ & \\
\hline Female & $622(52)$ & $1623(57.1)$ & \\
\hline Age group $(y)$ of the patient & & & \multirow{8}{*}{0.001} \\
\hline $1-10$ & $65(5.5)$ & $123(4.3)$ & \\
\hline $11-20$ & $97(8.2)$ & $196(6.9)$ & \\
\hline $21-30$ & $180(15.2)$ & $654(23.0)$ & \\
\hline $31-40$ & $260(22.0)$ & $1012(35.6)$ & \\
\hline $41-50$ & $144(12.2)$ & $536(18.8)$ & \\
\hline $51-60$ & $34(2.9)$ & $104(3.6)$ & \\
\hline $61-71$ & $27(2.3)$ & $76(2.6)$ & \\
\hline
\end{tabular}


The age of the patient was missing in $29.4 \%$ of the prescriptions. This was comparable with reported studies in hospitals of Italy (34.2\%) [11] and Indonesia (31\%) [14]. The signature on the prescription expresses the legality of the prescription [15]. In the current study, $26.5 \%$ of the prescriptions were not signed by the prescribers. This is lower than the number reported in Saudi Arabia (41.7 \%) [16]. Our study highlighted that the frequency of prescription errors were most common in the age group of $30-40$ years of age (1,012 representing $35.36 \%)$, followed by the age group of 21-30 years (23.0 $\%$ ), and the age group of $41-50$ years (18.8 \%). These results were consistent with a study conducted in Spain, where the prescription errors in the adolescent age were $31.7 \%$ [17].

The present study revealed that the incidence of prescription errors was more common in teaching hospitals (472 representing $39.9 \%$ ), as compared to DHQs (329 representing $27.8 \%$ ), and private hospitals (355 representing $30.0 \%$ ). These findings were consistent with the reported studies from Malaysia, Oman, and Turkey $[18,19]$. This high frequency of prescription errors in teaching hospitals may be due to patient burden and non-uniformity of patient distribution.

The frequency of prescription errors was higher in the prescriber group with higher qualifications $(p=0.001)$, which was consistent with the reported study from Malaysia ( $p=0.008$ ) [20]. The greater frequency of prescription errors in prescribers with higher qualifications may be due to a higher patient load and non-uniform distribution of patients. According to the Pakistan Bureau of Statistics, the total population of Pakistan is 220 million, and the number of doctors registered with Pakistan Medical Council is 1.1 million, which shows that doctor to population ratio is $1: 1764$. This ratio is too high, compared to the World Health Organization standard ratio, that is, $1: 1,000$.

\section{Limitations of the study}

In the presented study, the prescription was collected from urban areas, and hence prescription errors may be different in rural areas which were not included in the study. Moreover, most of the prescriptions were from people of adult age; in prescriptions for older age groups, the incidence of errors may be different.

\section{CONCLUSION RECOMMENDATIONS}

AND

The findings of this study reveal that there is a higher degree of prescription errors in the most populous province of Pakistan (Punjab). The major reason for the passing of these prescription errors from prescribers to the patients may be linked to the absence of pharmacists in community pharmacies. The role of pharmacists should be incorporated to overcome these problems in the health care system of Pakistan. The government should take the necessary measures to facilitate the implementation of electronic prescribing and Computerized Physician Order Entry (CPOE), along with the Clinical Decision Support System (CDSS). The professional medical associations should start mandatory Continuing Medical Education (CME) programs for prescribers. Health Administration authorities should devise mechanisms for the uniform distribution of patient load amongst prescribers working in different hospitals.

\section{DECLARATIONS}

\section{Acknowledgement}

The authors are very grateful to the Management of the hospitals in the major cities of Punjab, Pakistan for their kind cooperation and support.

\section{Conflict of interest}

No conflict of interest is associated with this work.

\section{Contribution of authors}

We declare that this work was done by the authors named in this article and all liabilities pertaining to claims relating to the content of this article will be borne by the authors.

\section{Open Access}

This is an Open Access article that uses a funding model which does not charge readers or their institutions for access and distributed under the terms of the Creative Commons Attribution License (http://creativecommons.org/licenses/by/ 4.0) and the Budapest Open Access Initiative (http://www.budapestopenaccessinitiative.org/rea d), which permit unrestricted use, distribution, and reproduction in any medium, provided the original work is properly credited.

\section{REFERENCES}

1. Kumari $R$, Idris $M$, Bhushan V, Khanna A, Agrawal M, and Singh SK. Assessment of prescription pattern at the

Trop J Pharm Res, January 2021; 20(1): 200 
public health facilities of Lucknow district. Indian J. Pharmacol. 2008; 40(6): 243-247.

2. Ajoke $A B$ and Christiana EU. Study of completeness of prescriptions in paediatrics emergency section of a tertiary hospital in Lagos. Nigeria. J. Appl. Pharm 2013; 3(5): 75-79.

3. World Health Organization. Guide to Good Prescribing- A Practical Manual. 1994: 115-142.

4. Hussain A, Ibrahim MI and Baber ZD. Compliance with legal requirements at community pharmacies: a cross sectional study from Pakistan. Int J Pharm Pract. 2012; 20(3): 183-190.

5. Dean B, Schachter M, Vincent $C$ and Barber N. Causes of prescribing errors in hospital inpatients: a prospective study. The Lancet. 2002; 359(9315): 1373-1378.

6. Bates DW. Preventing medication errors: a summary. Am. J. Health-Syst. Pharm. 2007; 64(14_Supplement_9): 53-59

7. Ali M, Abbasi BH, Ahmad N, Fazal H, Khan J, and Ali S.S. Over-the-counter medicines in Pakistan: misuse and overuse. The Lancet, 2020; 395(10218): 13731378.

8. Davis $L$ and Drogasch $M$. Triple check procedure prevents chemotherapy errors. Oncol Nurs Forum. 1997; 24(4): 641-2.

9. Atif M, Azeem M, Sarwar MR, Malik I, Ahmad W, Hassan $F$, Rehman A, and Rana M. Evaluation of prescription errors and prescribing indicators in the private practices in Bahawalpur, Pakistan. J Chin Med Assoc. 2018; 81(5): 444-449.

10. Mahmood KT, Amin F, Tahir M, and Haq I.U. Pharmacovigilance-a need for best patient care in Pakistan. A review. J. Pharm. Sci. Res., 2011; 3(11): 1566-1584.
11. Velo GP and Minuz $P$. Medication errors: prescribing faults and prescription errors. $\mathrm{Br} J$ Clin Pharmacol. 2009; 67(6): 624-628.

12. Stubbs J, Haw C, and Taylor D. Prescription errors in psychiatry-a multi-centre study. J. Psycho pharmacol. (Oxford). 2006; 20(4): 553-561.

13. Mohan $P$, Sharma A, and Panwar S. Identification and quantification of prescription errors. Med $J$ Armed Forces India. 2014; 70(2): 149-153.

14. Perwitasari, DA, Abror J, and Wahyuningsih I. Medication errors in outpatients of a government hospital in Yogyakarta Indonesia. Int. J. Pharm. Sci. Rev. Res. 2010; 1(1): 8-10.

15. Katzung BG. Rational Prescribing \& Prescription Writing. Basic \& Clinical Pharmacology. 2018: 1146-1168.

16. Kamel FO, Alwafi HA, Alshaghab MA, Almutawa ZM, Alshawwa LA, Hagras MM, Park YS and Tekian AS. Prevalence of prescription errors in general practice in Jeddah, Saudi Arabia. Med Teach. 2018; 40(sup1): 522-529.

17. Fernández-Llamazares $C M$, Pozas $M$, Feal $B$, Cabañas MJ, Villaronga $M$, Hernández-Gago $Y$, De Villegas $M R$ and Álvarez-del-Vayo C. Profile of prescribing errors detected by clinical pharmacists in paediatric hospitals in Spain. Int J Clin Pharm. 2013; 35(4): 638-646.

18. Gider Ö, Ocak S, and Top M. Evaluation of electronic prescription implications in turkey: an investigation of the perceptions of physicians. Worldviews Evid Based Nurs. 2015; 12(2): 88-97.

19. Shahaibi NM, Al Said LS, Chitme $H$, and Kini $T$. Identifying errors in handwritten outpatient prescriptions in Oman. J Young Pharm. 2012; 4(4): 267-272.

20. Norsa adah B, Norbanee $T$, Zaliha I and Wil AC. Prescription writing errors by doctors at Pasir Mas Hospital. Tokyo Jikeikai Ika Daigaku Zasshi. 2006; 13(1): 15-18. 